\title{
Effect of Hydrogen on Fatigue Crack Growth of Metals
}

\author{
Yukitaka Murakami ${ }^{1}$ \\ ${ }^{1}$ Kyushu University and The Research Center for Hydrogen \\ Industrial Use and Storage (HYDROGENIUS), AIST, \\ 744 Moto-Oka, Nishi-ku, Fukuoka, 819-0395 JAPAN \\ ymura@mech.kyushu-u.ac.jp
}

\begin{abstract}
Keywords: Hydrogen Embrittlement, Fatigue, Crack Growth Rate, Hydrogen Diffusion, Frequency Effect, Slip Localization
\end{abstract}

\begin{abstract}
.
The materials used for the components of fuel cell vehicles(FCVs), and stationary fuel cell(SFC) systems, equipment for hydrogen stations, hydrogen pipilines and transport systems are directly exposed to high-pressure hydrogen. To realize these technologies, a particularly difficult scientific problem termed "hydrogen embrittlement(HE)" must be solved. Although the term HE has been widely used to describe the phenomenon, no unifying theory has been established and little work has been directed towards understanding the mechanisms in cyclic loading..
\end{abstract}

The present paper overviews the recent progress on HE obtained at HYDROGENIUS.

Most research on HE over the past 40 years has paid insufficient attention to two points that are crucially important in the elucidation of the true mechanism. One is that, in most studies, the hydrogen content of specimens was not directly measured. Second, detailed studies that have quantified the influence of hydrogen on fatigue crack growth behaviour, based on microscopic observations are very rare; most studies have only examined the influence of hydrogen on tensile properties.

The present paper shows several important phenomena obtained by investigations of the effect of hydrogen on fatigue crack growth behaviour, including the measurement of the hydrogen content in various materials such as low-carbon, $\mathrm{Cr}-\mathrm{Mo}$ and stainless steels. Particularly important phenomena are the localization of fatigue slip bands, strain-induced martensite in types 304, 316 and even 316L, and also strong frequency effects on fatigue crack growth rates. For example, with a decrease in frequency of fatigue loading down to the level of $0.2 \mathrm{~Hz}$, the fatigue crack growth rate of a Cr-Mo steel is accelerated by 10-30 times. The same phenomenon also occurs even in austenitic stainless steels at the frequency of the level of $0.001 \mathrm{~Hz}$. Striation morphology is also influenced by hydrogen.

These detailed observations and measurements have allowed us to make quantitative estimates of the effect of hydrogen on cyclic crack growth.

\section{Introduction}

In order to enable the "hydrogen society (or hydrogen economy)" in the near future, a number of pressing technical problems must be solved. One important task for mechanical engineers and material scientists is the development of materials and systems which are capable of withstanding the effects of cyclic loading in hydrogen environments. In the past much research has been concentrated on the phenomenon known as hydrogen embrittlement [1-3]. Hydrogen effects on slip localization [2-4], softening and hardening [4-12], hydrogen-dislocation interactions [12-14] and creep [15] have been also reported. However, most research on HE over the past 40 years has paid insufficient 
attention to two points that are crucially important in the elucidation of the true mechanism. One is that, in most studies, the hydrogen content of specimens was not directly measured. Second, detailed studies that have quantified the influence of hydrogen on fatigue crack growth behaviour, based on microscopic observations are very rare; most studies have only examined the influence of hydrogen on tensile properties[16-33]. In order to produce components which must perform satisfactorily in service for up to 15 years, there is an urgent need for basic, reliable data on the fatigue behaviour of candidate materials in hydrogen environments.

Two typical fuel cell (FC) systems are the stationary FC system and the automotive FC (Fuel Cell Vehicle, FCV) system. In the FCV system, many components such as the liner of high pressure hydrogen storage tank, valves, pressure sensors, hydrogen accumulators, pipes, etc, are exposed to high pressure hydrogen environment for a long period up to 15 years. Sufficient data have not been obtained on the content of hydrogen which diffuses into metals during a long period of exposure to hydrogen. "How much hydrogen is contained in components in the fuel cell related system?" is a very important question. But this question is difficult to answer.

Figure 1 shows the hydrogen content in three steels which were exposed to 76-78MPa hydrogen for $100 \mathrm{hrs}$ at $110^{\circ} \mathrm{C}$. We need to know not only the hydrogen content but also the effect of hydrogen content on fatigue properties. The effect of hydrogen on fatigue properties of metals is different depending on materials, i.e. microstructures.
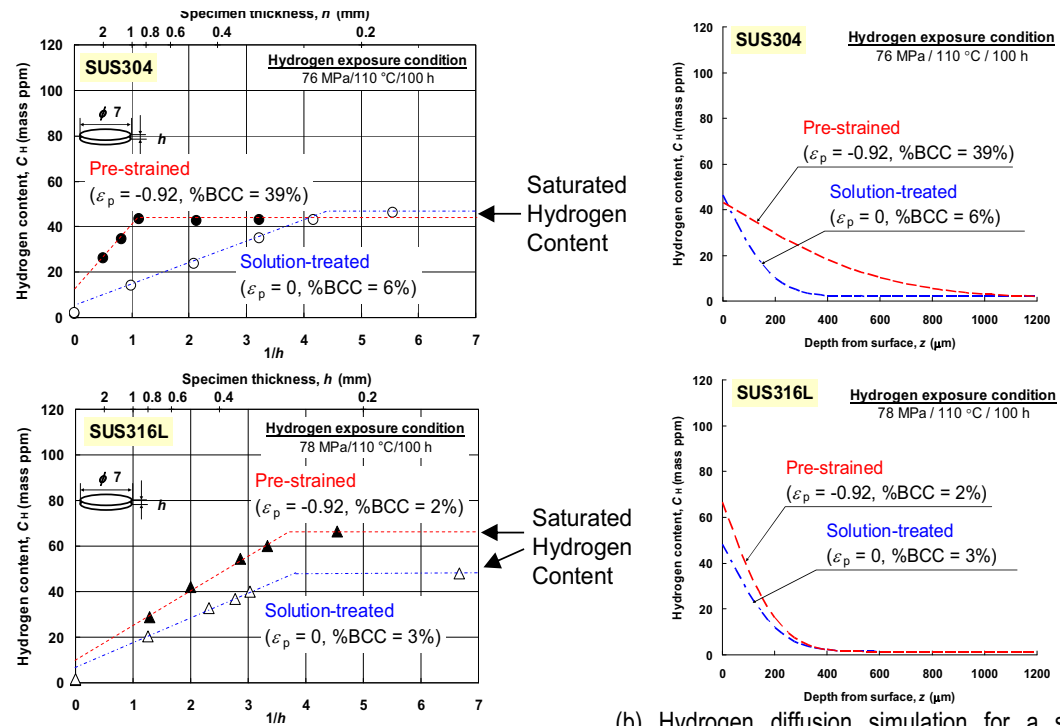

(a) Relationship between specimen thickness and hydrogen content in SUS304 and SUS316L exposed to high-pressure hydrogen.

(b) Hydrogen diffusion simulation for a semi-infinite material based on the exposure experiment.

Fig. 1 The effect of hydrogen entry behaviour into stainless steels[39]

The effect of hydrogen on high cycle fatigue was discovered by chance in course of the research to study the elimination phenomenon of the conventional fatigue limit in high strength steels. In high strength steels cycled into the very high cycle range fatigue cracks are often initiated at sub-surface inclusions. In 1998 Murakami et. al. [34, 35] pointed out that in these steels, hydrogen trapped by nonmetallic inclusions can play a crucially important role in the early stages of the fatigue crack growth process. Observations made with the aid of an optical microscope of the fracture origin revealed that an Optically Dark Area (ODA) was present around inclusions, as shown in Fig. 2. The 
hydrogen trapped by the inclusion at fracture origin was clearly quantified by the Secondary Ion Mass Spectrometry (SIMS)[36] and the tritium autoradiography[37].

In the present paper, the fatigue properties obtained in hydrogen environments of several steels which are candidate materials for use in fuel cell (FC) systems are presented. In addition, a number of interesting aspects of the effect of hydrogen on fatigue properties and fatigue mechanisms will be discussed.

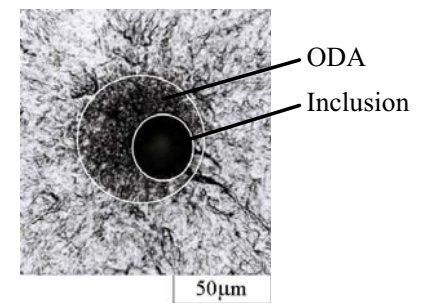

Fig. 2 Optical micrograph of the fracture origin (SCM435, $\left.\sigma_{\mathrm{a}}=561 \mathrm{MPa}, N_{\mathrm{f}}=1.11 \times 10^{8}\right)$. ODA: Optically Dark Area[34,35]

\section{MATERIALS AND EXPERIMENTAL METHODS}

A. Materials and specimens. The materials used in this study are a Cr-Mo steel JIS SCM435 and round bars of two kinds of austenitic stainless steels (Type 304 stainless steel and Type 316L stainless steel). Table 1 shows the chemical compositions and the Vickers hardnesses (Load: $9.8 \mathrm{~N}$ ) of these materials. The round bars of Type 304 and Type $316 \mathrm{~L}$ were solution-heat-treated. The solution-heat-treatment was performed by water-quenching after keeping temperature at $1050{ }^{\circ} \mathrm{C}$ for $2 \mathrm{~min}$. for Type 304 and $10 \mathrm{~min}$. for Type 316L. The non-diffusible hydrogen content of the solution-treated specimen is $2.2 \mathrm{wppm}$ for Type 304 and $2.6 \mathrm{wppm}$ for Type 316L. Hydrogen contents were measured by the thermal desorption spectrometry (TDS) using a quadruple mass spectrometer. The measurement accuracy of the TDS is $0.01 \mathrm{wppm}$. However, non-diffusible hydrogen has not previously been suspected as the cause of hydrogen embrittlement. Figures 3 (a) and (b) show the fatigue specimen dimensions and the dimensions of the small hole which was introduced into the specimen surface. After polishing with \#2000 emery paper, the specimen surface was finished by buffing using colloidal $\mathrm{SiO}_{2}(0.04 \mu \mathrm{m})$ solution. A small artificial hole, $100 \mu \mathrm{m}$ diameter and $100 \mu \mathrm{m}$ deep, was drilled into the specimen surface as a fatigue crack growth starter. In the hydrogen-charged specimens, the specimen surface was buffed after hydrogen charging, and the hole was then introduced immediately.

Table 1 Chemical composition (w\%, *wppm) and Vickers hardness $H V$

\begin{tabular}{lccccccccccc}
\hline & $\mathrm{C}$ & $\mathrm{Si}$ & $\mathrm{Mn}$ & $\mathrm{P}$ & $\mathrm{S}$ & $\mathrm{Ni}$ & $\mathrm{Cr}$ & $\mathrm{Mo}$ & $\mathrm{Cu}$ & $\mathrm{H}^{*}$ & $H V$ \\
\hline SCM43 & 0.37 & 0.18 & 0.78 & 0.025 & 0.015 & 0.09 & 1.05 & 0.15 & 0.1 & & 330 \\
5 & 0.06 & 0.36 & 1.09 & 0.030 & 0.023 & 8.19 & 18.66 & - & & 2.2 & 176 \\
304 & 0.019 & 0.78 & 1.40 & 0.037 & 0.010 & 12.08 & 17.00 & 2.04 & & 2.6 & 157 \\
316L & & & & & & & & & & & \\
\hline
\end{tabular}

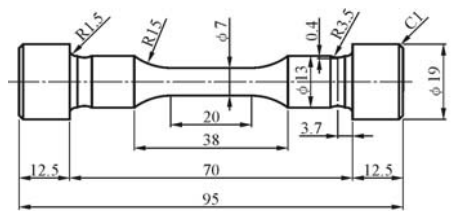

(a) Tension-compression specimen

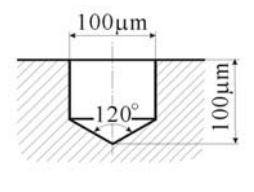

(b) Small artificial hole

Fig. 3 Dimensions of the fatigue test specimen and drilled hole 
The amount of martensite at the specimen surface, and at the fracture surfaces, of austenitic steel specimens was measured by the X-ray diffraction method, using monochromatic $\mathrm{Cr} \mathrm{K} \alpha$ radiation. The martensite content was evaluated by the ratio of the integrated intensity of the $\{220\}$ austenite peaks and the $\{211\}$ martensite peaks. The amount of martensite before fatigue testing in the Type 304 and Type $316 \mathrm{~L}$ specimens was approximately $3 \%$ at most. It should be noted that the amount of martensite measured by the X-ray diffraction method also includes the amount of $\delta$-ferrite.

B. Method of hydrogen charging. Hydrogen was charged into the specimens of SCM435 by soaking them in a $20 \%$ ammonium thiocyanate solution $\left(\mathrm{NH}_{4} \mathrm{SCN}\right)$. Hydrogen charging into the specimens of stainless steels was carried out either by cathodic charging [38] or by exposure to high pressure hydrogen gas. The high pressure hydrogen gas exposure was carried out in $63 \mathrm{MPa}$ hydrogen gas at $110{ }^{\circ} \mathrm{C}$ for $91 \mathrm{~h}$. The high pressure hydrogen gas was produced by the method developed by Mine et al.[39] using the hydrogen absorption and desorption process of a metal hydride.

C. Method of fatigue testing. Fatigue tests of the hydrogen-charged and uncharged specimens were carried out at room temperature in laboratory air. The fatigue tests for SCM435 were conducted at a stress ratio $R=-1$ and at a testing frequency between $0.02 \mathrm{~Hz}$ and $20 \mathrm{~Hz}$.

The fatigue tests for stainless steels were conducted at a stress ratio $R=-1$ and at a testing frequency of $1.5 \mathrm{~Hz}$ by tension-compression cyclic loading (sine wave). Fatigue tests at very low frequency were carried out to investigate the effects of hydrogen and test frequency on fatigue crack growth. In the very low frequency fatigue tests, the fatigue tests were first carried out at $1.5 \mathrm{~Hz}$, until the fatigue crack length $2 a$ reached $200 \mu \mathrm{m}$, followed by testing at $0.0015 \mathrm{~Hz}(11 \mathrm{~min} / \mathrm{cycle})$. The replica method was used for the measurements of crack length, and for the observation of crack growth behaviour. Following the fatigue tests, in order to measure the hydrogen content remaining in specimens, $0.8 \mathrm{~mm}$ thick disks were immediately cut from each specimen, under water-cooling. Then, hydrogen contents of disks were measured by TDS. Measurements were carried out up to $800^{\circ} \mathrm{C}$ at a heating rate of $0.5^{\circ} \mathrm{C} / \mathrm{s}$. It was confirmed that cutting disks from a specimen did not affect hydrogen content of disk sample[38].

\section{RESULTS AND DISCUSSION}

\section{II-1 Effect of Hydrogen on Fatigue Behaviour of Cr-Mo steel SCM435}

Cr-Mo steel: JIS SCM435 is a candidate material for the hydrogen storage cylinder of hydrogen station equipped with $35 \mathrm{MPa}$ hydrogen supply to FCV. The effect of hydrogen on fatigue crack behaviour of SCM435 was investigated in details by H. Tanaka et al [40]. In this paper, a part of their work will be introduced.

Figure 4 shows the relationship between crack length $a$ and number of cycle $N$ under the tensioncompression stress amplitude $\sigma_{a}=600 \mathrm{MPa}$. The fatigue crack growth rate $\mathrm{d} a / \mathrm{d} N$ of the hydrogen charged specimens is much higher than the uncharged specimens. Another important point is that $\mathrm{d} a / \mathrm{d} N$ increases with decreasing test frequency. It is presumed that there is sufficient time for hydrogen to diffuse and concentrate at crack tip under low test frequency.

Figure 5 shows the relationship between $\mathrm{d} a / \mathrm{d} N$ and stress intensity factor range $\Delta K$. Figure 6 shows the relationship between the acceleration of crack growth rate defined by the ratio of $\mathrm{d} a / \mathrm{d} N$ with hydrogen to $\mathrm{d} a / \mathrm{d} N$ in air and the test frequency $f$. The most important result in Figure 5 is that $\mathrm{d} a / \mathrm{d} N$ at $\Delta \mathrm{K}<17 \mathrm{MPa} \sqrt{\mathrm{m}}\left(\mathrm{d} a / \mathrm{d} N=1.0 \times 10^{-8} \mathrm{~m} /\right.$ cycle $-1.0 \times 10^{-7} \mathrm{~m} /$ cycle $)$ and $f<2 \mathrm{~Hz}$ for the hydrogen charged specimens are merged into one line regardless of the value of $f$ and the crack growth rates under these conditions are 30 times higher than those for uncharged specimens.

This frequency tendency can also be confirmed by Fig. 6. This tendency can be explained as follows. At very low crack growth rate $\mathrm{d} a / \mathrm{d} N<1.0 \times 10^{-7} \mathrm{~m} /$ cycle, hydrogen has sufficient time to 
diffuse into the crack tip process zone, because the location of crack tip does not move so much distance toward the direction of crack extension and the crack tip stays inside the process zone until hydrogen concentrates. On the other hand, for $\mathrm{d} a / \mathrm{d} N>1.0 \times 10^{-7} \mathrm{~m} / \mathrm{cycle}$, it is presumed that crack passes the process zone at crack tip before hydrogen concentrates and the rate of acceleration of $\mathrm{d} a / \mathrm{d} N$ varies depending on test frequency. However, regardless of the values of frequency, $\mathrm{d} a / \mathrm{d} N$ of hydrogen charged specimens gradually merges to the line of $\mathrm{d} a / \mathrm{d} N$ of uncharged specimens at higher value of $\mathrm{d} a / \mathrm{d} N$, because crack grows much faster than hydrogen diffusion to crack tip. Thus, the crack growth rate and hydrogen effect are mutually coupled.

The dotted line of Fig. 5 shows approximately 30 times acceleration of fatigue crack growth rate in presence of hydrogen and can be considered to be the upper bound of hydrogen effect which should be used for the fatigue life prediction design of hydrogen storage cylinder.

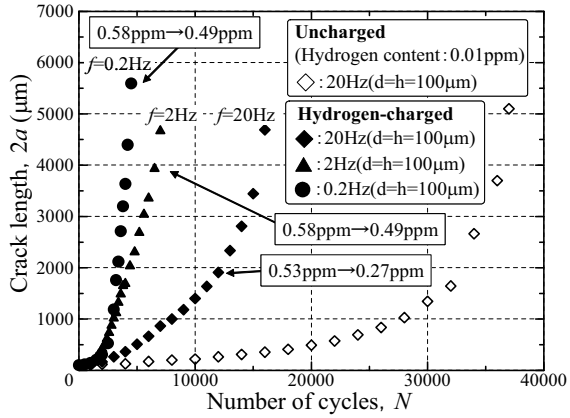

Fig.4 Relationship between crack length $2 a$ and number of cycles $N . \sigma_{\mathrm{a}}=600 \mathrm{MPa}$.

Material: SCM435

(H. Tanaka, et al[40])

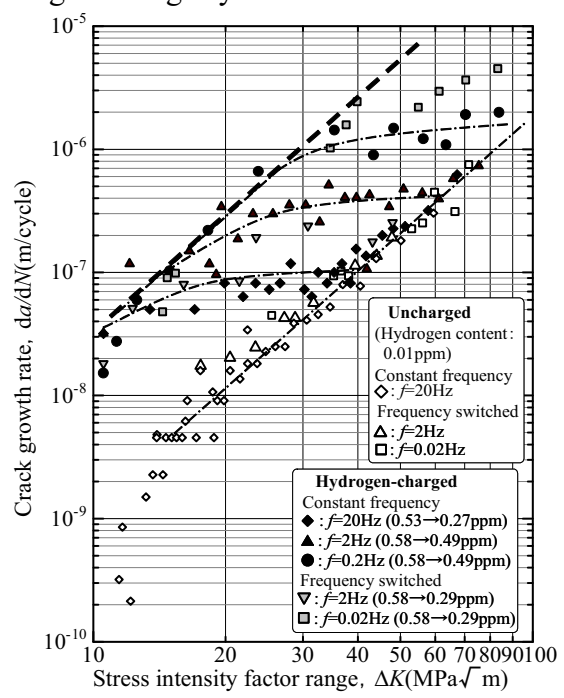

Fig. 5 Relationship between $\mathrm{d} a / \mathrm{d} N$ and $\Delta K$. Material: SCM435

(H.Tanaka, et al[40])

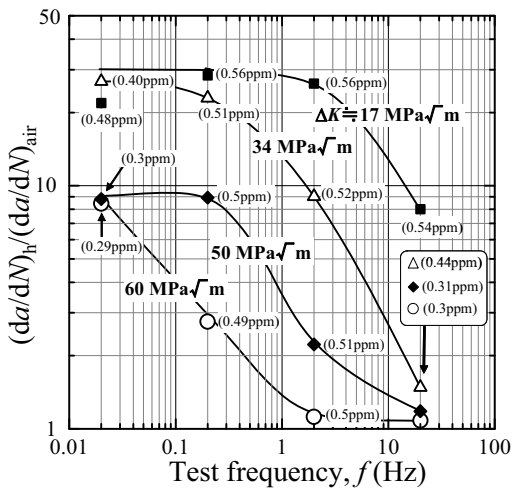

Fig.6 Relationship between acceleration of crack growth rate $(\mathrm{d} a / \mathrm{d} N)_{\mathrm{h}} /(\mathrm{d} a / \mathrm{d} N)_{\text {air }}$ and frequency $f$.

Material: SCM435 (H. Tanaka, et al[40]) 
Figure 7 shows the crack shapes and slip bands morphologies. The crack of the hydrogen charged specimen looks thinner than the uncharged specimens. The crack paths of the hydrogen charged specimens tested under $f=0.2$ and $2 \mathrm{~Hz}$ are relatively more linear than those of the uncharged specimens and also that of the hydrogen charged specimen tested under $f=20 \mathrm{~Hz}$. The crack tip of the uncharged specimen has many slip bands spreaded broad beside the crack line. On the other hand, the slip bands of the hydrogen charged specimens are localized only at very narrow area beside the crack line. Kanezaki, et al [38] reported the same slip localization at crack tip and linear crack path in the fatigue of hydrogen charged austenitic stainless steels.

In order to make clear the mechanism of slip bands localization and linear crack path more in details, the following fatigue tests were carried out.

1. First, the fatigue test was carried out at $f=2 \mathrm{~Hz}$ and the crack growth behaviour was observed by the replica method.

2. Second, the test frequency of the fatigue test was switched to $f=0.02 \mathrm{~Hz}$ and the crack growth behaviour was observed by the replica method.

These two step fatigue tests were repeated and the variation of the crack growth behaviour by switching the test pattern from 1 to 2 was observed. The results of these tests were very interesting as described in the following.

Figures 8(a) and (b) show the overall crack growth paths. The crack path of the uncharged specimens is monotonic and show no particular variation even after switching the test frequency from $f=2 \mathrm{~Hz}$ to $0.02 \mathrm{~Hz}$ and also from $0.02 \mathrm{~Hz}$ to $2 \mathrm{~Hz}$. The monotonic moderate curving of the crack of Fig. $8(\mathrm{a})$ is caused by the growth of plastic zone size due to increase in $a$, i.e. $\Delta K$. Namely, the plane stress condition is gradually satisfied and the crack extension by shear mode ahead of crack tip becomes dominant near specimen surface.

However, the crack of the hydrogen charged specimen for $\Delta K>40 \mathrm{MPa} \sqrt{\mathrm{m}}$, the influence of switching the test frequency appears very clearly in the variation of slip bands morphologies and crack path. The crack grows in the inclined direction under $f=2 \mathrm{~Hz}$, though the crack grows straight under $f=0.02 \mathrm{~Hz}$. Figure $8(\mathrm{c})$ is the magnification of the localization of slip bands in the region of $f=$ $0.02 \mathrm{~Hz}$. As shown by the marks $\square$ and $\nabla$ in Fig. 5, the $\mathrm{d} a / \mathrm{d} N$ under $f=0.02 \mathrm{~Hz}$ in this region ( $\square$ ) is approximately 10 times faster than $\mathrm{d} a / \mathrm{d} N$ under $f=2.0 \mathrm{~Hz}$. The cause for the difference between the inclined crack growth for $f=2 \mathrm{~Hz}$ and the linear crack growth for $f=0.02 \mathrm{~Hz}$ can be interpreted as follows.

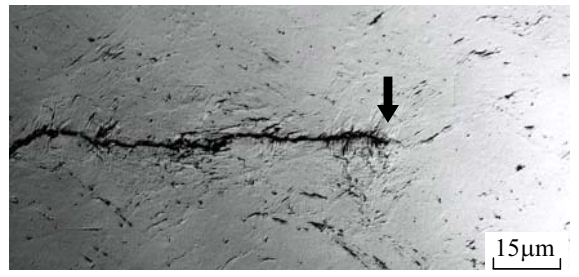

(a) Uncharged specimen, $\sigma_{\mathrm{a}}=600 \mathrm{MPa}, f=20 \mathrm{~Hz}$

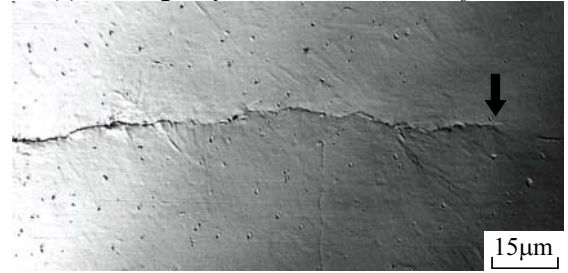

(c) Hydrogen- charged specimen, $\sigma_{\mathrm{a}}=600 \mathrm{MPa}, f=2 \mathrm{~Hz}$

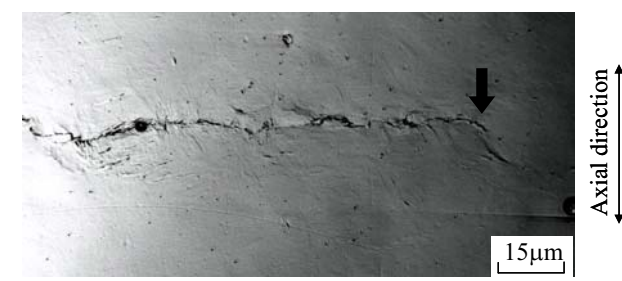

(b) Hydrogen-charged specimen, $\sigma_{\mathrm{a}}=600 \mathrm{MPa}, f=20 \mathrm{~Hz}$

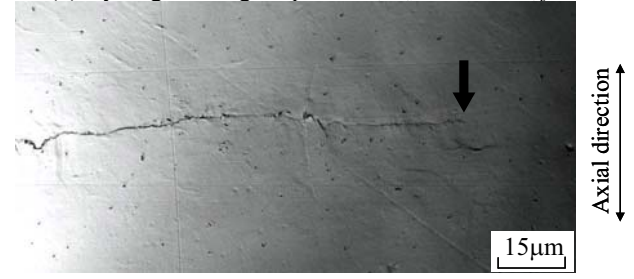

(d) Hydrogen-charged specimen, $\sigma_{\mathrm{a}}=600 \mathrm{MPa}, f=0.2 \mathrm{~Hz}$

Fig.7 Slip bands and fatigue cracks in uncharged and hydrogen-charged specimens at $\Delta K \doteqdot 20 \mathrm{MPa} \sqrt{\mathrm{m}}$. Material: SCM435

(H. Tanaka, et al [40]) 


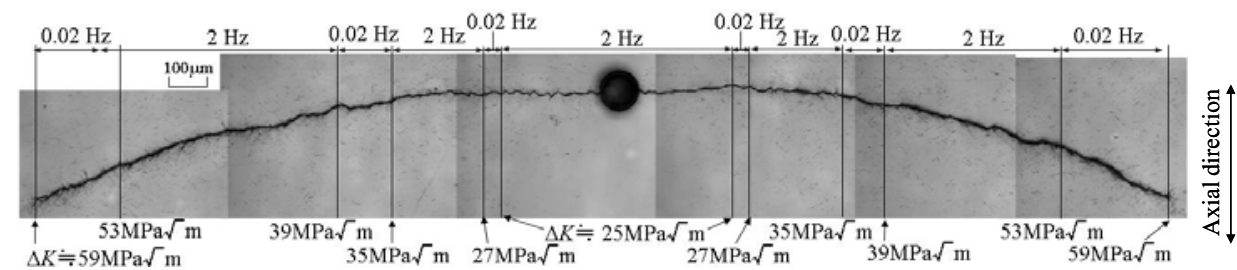

(a) Crack path in the uncharged specimen.

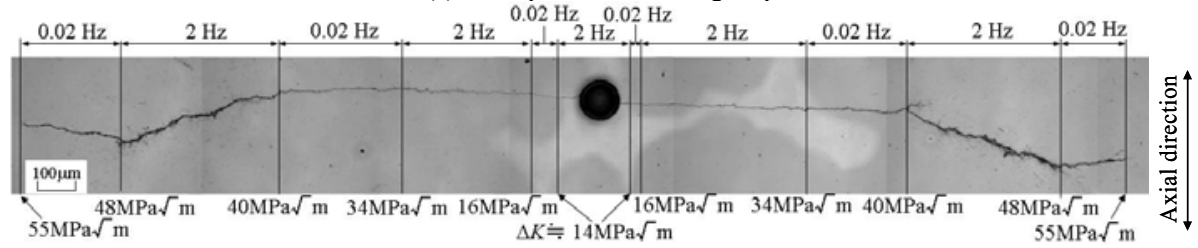

(b) Crack path in the hydrogen-charged specimen.

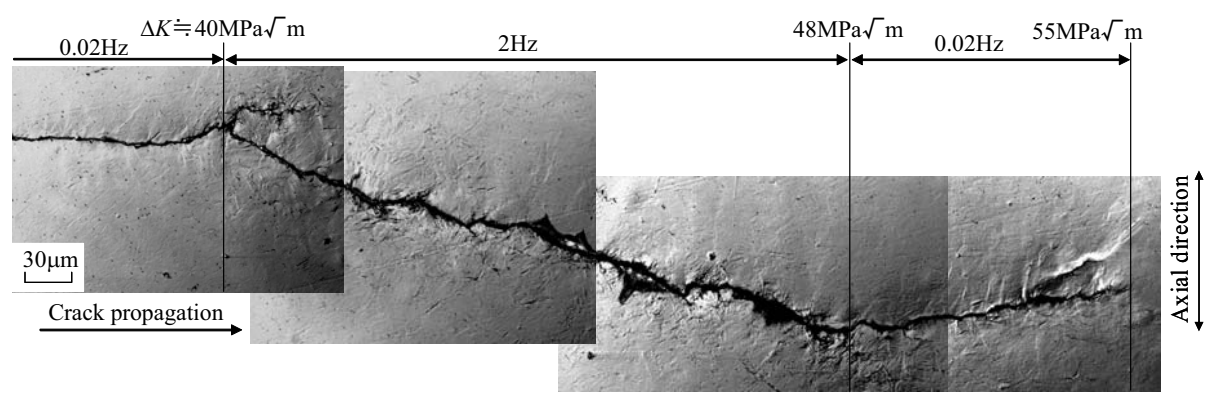

(c) Crack path and slip bands in the hydrogen-charged specimen

Fig. 8 Fatigue crack path and slip bands for the test with two frequencies of $0.02 \mathrm{~Hz}$ and $2 \mathrm{~Hz}$ at $\sigma_{\mathrm{a}}=600 \mathrm{MPa}$, Material: SCM435 (H, Tanaka, et al [40])

As explained with respect to Fig. 7, hydrogen influences the localization of slip band and decreases the plastic zone size at crack tip. As the test frequency $f$ decreases, this hydrogen effect is enhanced, resulting the plane strain condition with smaller plastic zone size even at high $\Delta K$.

Thus, the inclined crack growth behaviour under $f=2 \mathrm{~Hz}$ in Fig. $8(\mathrm{~b})$ and (c) is due to large plastic zone size with less hydrogen effect which is almost similar to the case of Fig. 8(a). It must be noted that these inclined cracks are made by shear mode fracture and are inclined to specimen surface.

\section{II-2 Effect of Hydrogen on Fatigue Behaviour of Austenitic Stainless Steels [38,41]}

A. Hydrogen entry into austenitic stainless steels. Figure 9[41] shows the hydrogen desorption spectra for an uncharged Type 316L specimen (curve A), and for a hydrogen-charged specimen (curve B). The height of the peak at around $300{ }^{\circ} \mathrm{C}$, which indicates diffusible hydrogen, shows an increase due to hydrogen charging. On the other hand, the height of the peak at around $400{ }^{\circ} \mathrm{C}$, which indicates non-diffusible hydrogen, shows that there is no significant difference between the hydrogen-charged and uncharged specimens. It should be noted that $2.6 \mathrm{wppm}$ non-diffusible hydrogen is contained even in the uncharged Type 316L. Although the data are not shown in the figure, the hydrogen desorption spectra for Type 304 were similar to those for Type $316 \mathrm{~L}$. The uncharged Type 304 specimen contained 2.2 wppm non-diffusible hydrogen.

The hydrogen content distributions from the surface to below the surface were measured by the method developed by Kanezaki et al. [38]. Figure 10[38] shows the hydrogen content distributions for 
austenitic stainless steel specimens hydrogen-charged for $672 \mathrm{~h}$ at $50{ }^{\circ} \mathrm{C}$ by cathodic charging. It can be seen that hydrogen diffused only into a very thin surface layer $(100 \sim 200 \mu \mathrm{m})$ in the austenitic stainless steels. High hydrogen content existed only in the thin $100 \mu \mathrm{m}$ surface layer. Depending on the stainless steel grade, the hydrogen content in this layer varied from $10 \sim 60 \mathrm{wppm}$.

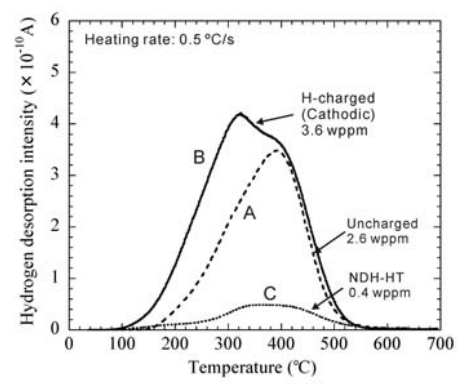

Fig. 9 Hydrogen thermal desorption spectrum of Type 316L[41]

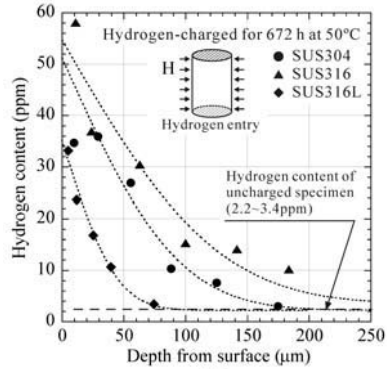

Fig. 10 Hydrogen content distributions of hydrogencharged specimens of three austenitic stainless steels. Charging method: Cathodic charging[38]

B. Effect of hydrogen on fatigue crack growth in solution-treated austenitic stainless steels; Results obtained by conventional fatigue testing. Figure 11[38] shows the fatigue crack growth curves starting from a hole in the uncharged and hydrogen-charged specimens of SUS304, SUS316 and SUS316L. The hydrogen content values in this figure were measured immediately after the fatigue test by TDS. For both SUS304 and SUS316, the increased fatigue crack growth rate due to increased hydrogen content is clear. The crack growth rate in the hydrogen-charged SUS316L was only slightly higher than the uncharged SUS316L. In the austenitic stainless steels, it can be assumed that hydrogen does not re-distribute macroscopically during the fatigue test (within $100 \mathrm{~h}$ ) because of the very low hydrogen diffusion coefficient, i.e., $D_{323 \mathrm{~K}} \sim 10^{-15} \mathrm{~m}^{2} / \mathrm{s}$. Thus, hydrogen loss during the fatigue test is considered to be negligible. Smith and Stewart[42] carried out fatigue tests at frequencies $0.02 \sim 50 \mathrm{~Hz}$ and showed that fatigue crack growth of $2 \mathrm{Ni}-\mathrm{Cr}-\mathrm{Mo}-\mathrm{V}$ steel was more accelerated by hydrogen at the lower test frequency. It must be noted that fatigue tests in the current study were performed at frequencies of $1.2 \sim 5 \mathrm{~Hz}$. The effect of test frequencies much lower than $1 \mathrm{~Hz}$ will be explained in the following sections.

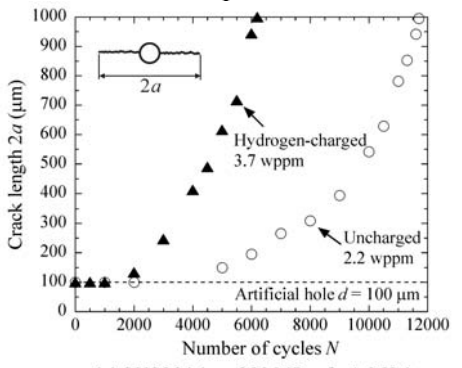

(a) SUS304 $(\sigma=280 \mathrm{MPa}, f=1.2 \mathrm{~Hz})$

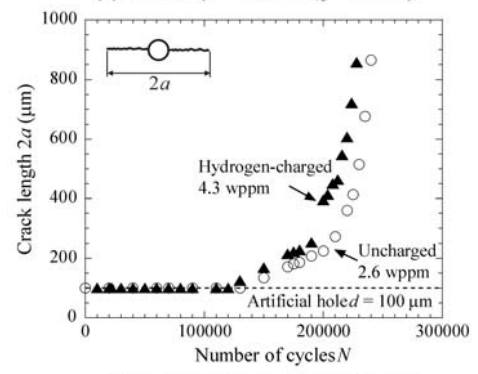

(c) SUS3 $16 \mathrm{~L}(\sigma=260 \mathrm{MPa}, f=5 \mathrm{~Hz})$

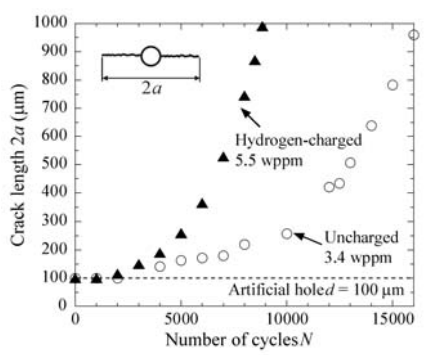

(b) $\operatorname{SUS} 316(\sigma=260 \mathrm{MPa}, f=1.2 \mathrm{~Hz})$

Fig. 11 Influence of hydrogen charging on crack growth from $100 \mu \mathrm{m}$ hole for austenitic stainless steels SUS304, SUS316 and SUS316L. Hydrogen charging was carried out at $50^{\circ} \mathrm{C}$ for 672 hours. Charging method: cathodic charging[38] 
C. Effects of hydrogen and test frequency on fatigue crack growth. Figure 12(a) and (b)[41] show the relationship between the crack length, $2 a$, and the number of cycles, $N$, for Type 304 and Type $316 \mathrm{~L}$ specimens. The hydrogen contents of the hydrogen-charged specimens, which were measured immediately after fatigue tests, are also included in the figure. The crack length is defined by adding the initial hole diameter. Figure 12(c) [41] shows the relationship between the fatigue crack growth rate, $\mathrm{d} a / \mathrm{d} N$, and the stress intensity factor range, $\Delta K$, for Type $316 \mathrm{~L}$. In Type $316 \mathrm{~L}$ tested at a frequency of $1.5 \mathrm{~Hz}$, there was no pronounced difference between the hydrogen-charged specimen and the uncharged specimen. The fatigue crack growth rates of the hydrogen-charged Type 316L, tested at the frequency $f=0.0015 \mathrm{~Hz}$, were 2 to 3 times higher than those of Type 316L tested at $f=$ $1.5 \mathrm{~Hz}$. In particular, in the $\Delta K$ range from 8 to $10 \mathrm{MPa} \cdot \mathrm{m}^{1 / 2}$, the increase in the crack growth rate was remarkable. Surprisingly, the uncharged specimen also exhibited an obviously definite crack growth rate increase as the test frequency decreased from $1.5 \mathrm{~Hz}$ to $0.0015 \mathrm{~Hz}$.

The crack growth rates of both the hydrogen-charged and uncharged specimens of Type $316 \mathrm{~L}$, tested at a frequency of $1.5 \mathrm{~Hz}$, are expressed by

$$
d a / d N=1.36 \times 10^{-11}(\Delta K)^{3.27} \text { for } 7 \mathrm{MPa} \cdot \mathrm{m}^{1 / 2}<\Delta K<25 \mathrm{MPa} \cdot \mathrm{m}^{1 / 2}
$$

On the other hand, the crack growth rates of the hydrogen-charged and uncharged specimens of Type $316 \mathrm{~L}$, tested at a frequency of $0.0015 \mathrm{~Hz}$, are expressed by

$$
d a / d N=1.78 \times 10^{-11}(\Delta K)^{3.52} \text { for } 7 \mathrm{MPa} \cdot \mathrm{m}^{1 / 2}<\Delta K<9 \mathrm{MPa} \cdot \mathrm{m}^{1 / 2}
$$

and

$$
d a / d N=6.26 \times 10^{-11}(\Delta K)^{2.91} \text { for } 9 \mathrm{MPa} \cdot \mathrm{m}^{1 / 2} \leq \Delta K<25 \mathrm{MPa} \cdot \mathrm{m}^{1 / 2}
$$

In the range of $\Delta K<9 \mathrm{MPa} \cdot \mathrm{m}^{1 / 2}$, the crack growth rate is slow and it is presumed that there is sufficient time for hydrogen to concentrate in the vicinity of crack tip during one cycle at a frequency of $0.0015 \mathrm{~Hz}$. Hence, both the values of $m$ and $C$ in Eq. (2) have larger values than those in Eq. (1). On the other hand, in the range of $\Delta K>9 \mathrm{MPa} \cdot \mathrm{m}^{1 / 2}$, the fatigue crack growth rates of the hydrogen-charged and uncharged specimens, tested at a frequency of $0.0015 \mathrm{~Hz}$, gradually increased and approached to those tested at a frequency of $1.5 \mathrm{~Hz}$, though the value of $C$ in Eq. (3) is larger than that in Eq. (1) and the value of $m$ in Eq. (3) is smaller than that in Eq. (1).

In Type 304 as well as in Type 316L, the uncharged specimen exhibited a definite frequency effect. As the test frequency decreased from $1.2 \mathrm{~Hz}$ to $0.0015 \mathrm{~Hz}$ fatigue crack growth rates increased (Fig. 12(a)).
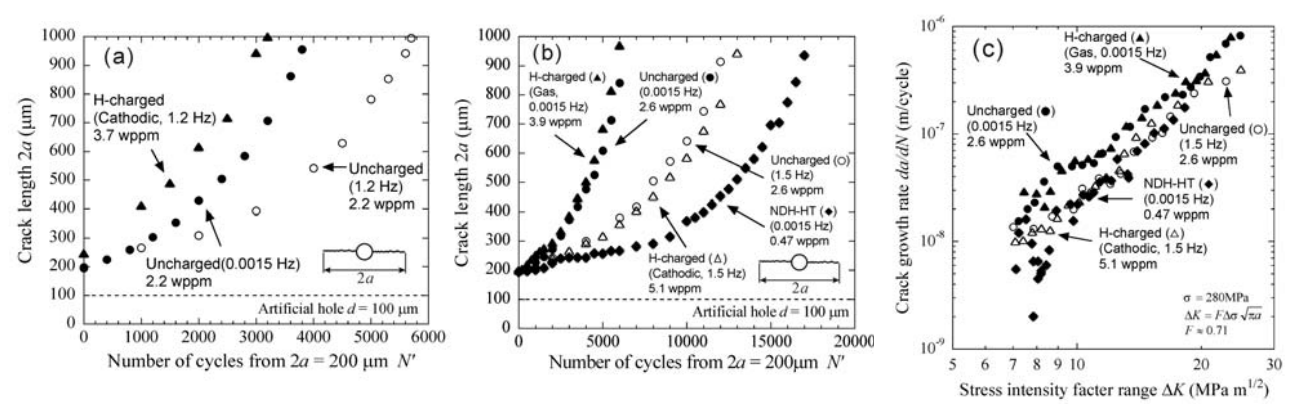

Fig. 12 Influence of hydrogen and test frequency on crack growth from $2 a=200 \mu \mathrm{m}$, of (a) type 304 ( $\sigma=280 \mathrm{MPa}$ ), (b) type $316 \mathrm{~L}(\sigma=280 \mathrm{MPa})$, and (c) effect of hydrogen and test frequency on crack growth rate of type 316L[41] 
Figure 13[41] shows micrographs of fatigue cracks taken by the replica method for Type 304 specimens. For Type 304 tested at a frequency of $1.2 \mathrm{~Hz}$, the fatigue crack in the hydrogen-charged specimen grew straighter than did that in the uncharged specimen. Slip bands in the hydrogen-charged specimen were more localized, in the vicinity of crack tips, compared to those in the uncharged specimen, which was tested at the same stress level, as shown in Fig. 13(a) and (c). Even for the uncharged Type 304 specimen, slip bands localization in the crack tip vicinity was observed in the low frequency test $(f=0.0015 \mathrm{~Hz})$, although the extent of the slip localization was less pronounced than for the hydrogen-charged Type 304 specimen $(f=1.2 \mathrm{~Hz}$, Fig. 13(c)). Although the fatigue test for hydrogen-charged Type 304 at a frequency of $0.0015 \mathrm{~Hz}$ was not carried out, the result can be easily predicted from the data of the Type 316L shown in Fig. 12. The slip bands in hydrogen-charged Type 304 tested at a frequency of $0.0015 \mathrm{~Hz}$ will be at least similar to that tested at a frequency of $1.2 \mathrm{~Hz}$, or will be more localized than that tested at a frequency of $1.2 \mathrm{~Hz}$, because, in the fatigue test at a frequency of $0.0015 \mathrm{~Hz}$, there is sufficient time for hydrogen to concentrate in the vicinity of crack tip during one cycle.

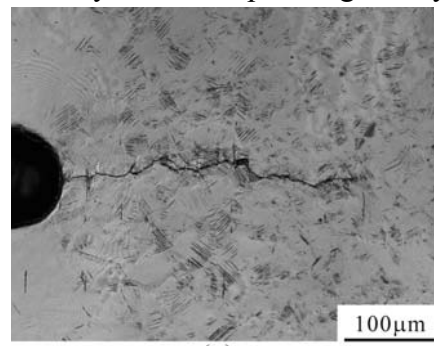

(a)

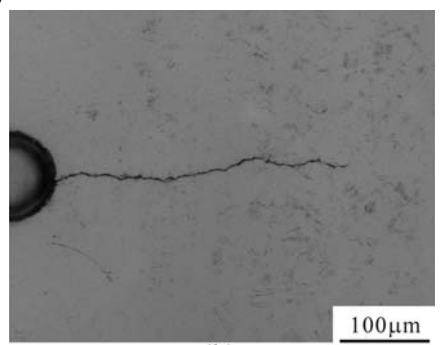

(b)

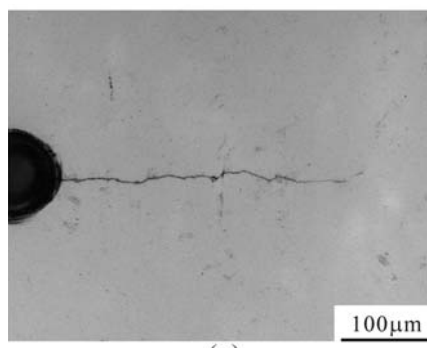

(c)

Fig. 13 Difference in crack growth behavior between hydrogen-charged specimens and uncharged speimens of type 304 ( $\sigma=280 \mathrm{MPa})$ : (a) uncharged $(f=1.2 \mathrm{~Hz}, 2 a=782 \mu \mathrm{m}, 2.2 \mathrm{wppm}),(\mathrm{b})$ uncharged $(f=0.0015 \mathrm{~Hz}, 2 a=$ $778 \mu \mathrm{m}, 2.2 \mathrm{wppm})$, and (c) H-charged ( $f=1.2 \mathrm{~Hz}, 2 a=801 \mu \mathrm{m}, 3.7 \mathrm{wppm})$ [41].

The authors' previous researches [38] have indicated that strain-induced martensitic transformation at the crack tip could be considered to be one of the main causes of crack growth rate increase due to hydrogen. Martensitic transformation must be considered as a crucial factor in the enhancement of hydrogen induced fatigue crack growth rate increases. In this regard, the authors measured the volume fraction of martensite on the fracture surfaces of Type 304 and Type 316L specimens tested at a frequency of $0.0015 \mathrm{~Hz}$. The volume fraction of martensite was determined by the microscopic X-ray diffraction technique. Strain-induced martensitic transformation occurred on fracture surfaces at both test frequencies: $f \sim 1.5 \mathrm{~Hz}$ and $0.0015 \mathrm{~Hz}$. It should be noted that even in Type $316 \mathrm{~L}$, which had previously been thought extremely difficult to transform to martensite at ambient temperature, martensitic transformation took place at fatigue crack tips. It should be also noted that martensitic transformation was detected only at the fatigue fracture surface and not at other places such as specimen surface even in Type 304 .

D. Effects of hydrogen on striation formation. The authors have reported that hydrogen decreased the area fraction of fatigue striations on the fatigue fracture surface in Type 304, and also that the ratio of striation height, $H$, to striation spacing $s, H / s$, was reduced for a hydrogen-charged specimen [38]. Taking these facts into consideration, striations observed on the fracture surfaces of Type 316L and Type 304 tested at the low frequency were therefore investigated. Figure 14 shows the topography of striations observed in the hydrogen-charged and uncharged Type 304 specimens tested under the same conditions. These topographies were obtained by constructing the $3 \mathrm{D}$ shape of striations by analysis of a pair of stereographic SEM images. In the uncharged specimen each striation was regularly formed and roughly triangular in shape. In the hydrogen-charged specimen, on the other hand, striations were irregularly shaped, and the striation height was lower compared to 


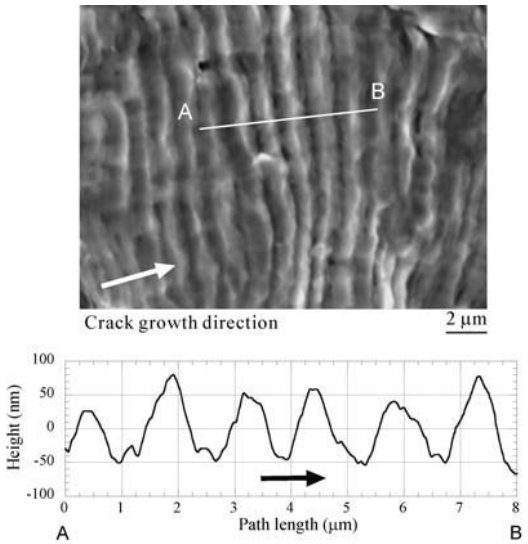

(a)

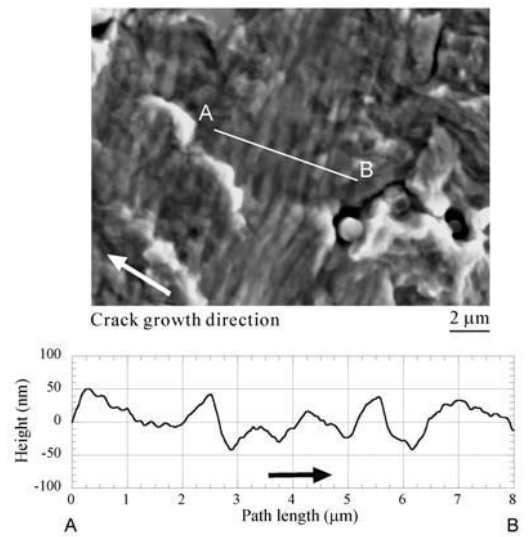

(b)

Fig. 14 Difference in striation morphology between a hydrogen-charged specimens and uncharged speimens of type 304: (a) uncharged $(\sigma=260 \mathrm{MPa}, f=1.5 \mathrm{~Hz}, 2.2 \mathrm{wppm})$ and (b) H-charged ( $\sigma=260 \mathrm{MPa}, f=1.5 \mathrm{~Hz}$, $6.7 \mathrm{wppm})$. The arrows in the figures indicate the crack growth directon.

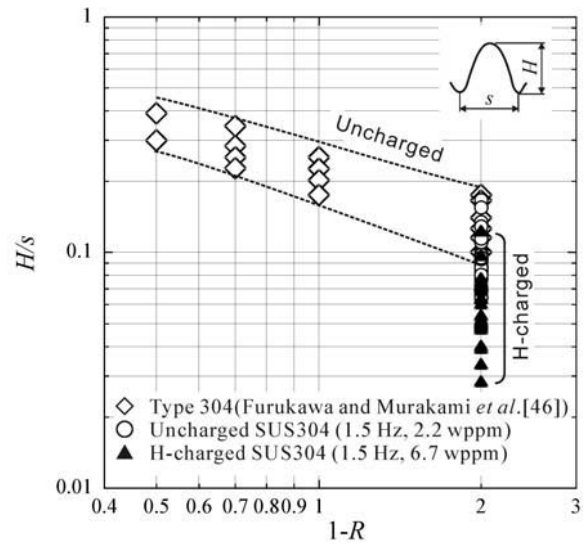

Fig. 15 Relationship between ratio of striation height $H$ to spacing $s, H / s$, and stress ratio (1-R).

that for the uncharged specimen. In previous work, Furukawa and Murakami et al. [43] obtained the topography of striations by cutting the fatigue fracture surfaces of Type 304 specimens with a microtome. They found a good correlation between the ratio, $H / s$ and the $R$ ratio. Figure 15 shows the $H / s$ data for Type 304 in the present study, together with Furukawa and Murakami et al.'s data. The figure indicates that the $H / s$ data obtained from the stereographic SEM images in this study, for the uncharged specimen tested at $f=1.5 \mathrm{~Hz}$, had a good correlation with Furukawa and Murakami et al.'s data.

Considering that the features of striation shape for the uncharged specimen, tested at the frequency of $0.0015 \mathrm{~Hz}$, are very similar to those for the hydrogen-charged specimen (Fig. 14(b)), it follows that testing at the low frequency $(f=0.0015 \mathrm{~Hz})$ enhances the hydrogen effect, even in the uncharged specimens which contain non-diffusible hydrogen at a level of $2 \sim 3$ wppm.

E. What happens if non-diffusible hydrogen is removed by the special heat treatment? Even in the uncharged specimens the fatigue crack growth rate is increased by decreasing the test 
frequency down to $0.0015 \mathrm{~Hz}$. The only suspect cause of this surprising phenomenon is the effect of non-diffusible hydrogen, of the level of $2 \sim 3 \mathrm{wppm}$, which is unavoidably trapped in the material during the production process. The non-diffusible hydrogen unavoidably contained in solution treated austenitic stainless steels is different from the diffusible (or reversible) hydrogen which is charged into a material by a hydrogen gas environment, or by electro-chemical methods. This non-diffusible hydrogen has not been suspected, in previous hydrogen embrittlement studies, as a possible cause of hydrogen embrittlement.

However, if this non-diffusible hydrogen can cause hydrogen embrittlement, it means that the hydrogen embrittlement of austenitic stainless steels can occur even in the absence of an external hydrogen environment.

In order to investigate the influence of so-called non-diffusible hydrogen on fatigue crack growth, a special heat treatment was applied. This is soaking Type $316 \mathrm{~L}$ at $450{ }^{\circ} \mathrm{C}$ for $450 \mathrm{~h}$, and Type 304 at $300{ }^{\circ} \mathrm{C}$ for $600 \mathrm{~h}$, in a vacuum of $6.0 \times 10^{-3} \mathrm{~Pa}$. In practice this heat treatment was carried out by enclosing specimens, or samples, in an evacuated silica glass tube. During the heat treatment process the partial pressure of hydrogen in the glass tube increases, and this prevents the removal of hydrogen in a specimen to below the equilibrium hydrogen content for the increased partial pressure. Therefore, in order to avoid unwanted increases in the hydrogen partial pressure, a specimen was removed from the glass tube after heat treatment for $150 \mathrm{~h}$, and the same vacuum heat treatment process was then repeated in $150 \mathrm{~h}$ increments. Fatigue testing was carried out using specimens which were prepared using the special heat treatment. The specification for this special heat treatment was determined by considering the temperature and time needed to avoid sensitization, and also to ensure hydrogen diffusion out of specimens. This heat treatment is completely different from the so-called 'baking' which is conventionally applied to remove hydrogen introduced by processes such as welding and plating. Non-diffusible hydrogen at the level of $2 \sim 3 \mathrm{wppm}$ cannot be removed by the so-called baking.

In this paper we call this special heat treatment Non-Diffusible Hydrogen desorption Heat Treatment (NDH-HT). The effect of NDH-HT is clearly shown in Fig. 9, in which the hydrogen content in an ordinarily heat treated Type $316 \mathrm{~L}$ is $2.6 \mathrm{wppm}$, and on the other hand in the sample subjected to NDH-HT the content is 0.4 wppm. Thus, NDH-HT removes the hydrogen, which is strongly trapped at the centre (O-site) of an octahedron of the FCC lattice, where the potential energy is much lower than that for hydrogen trapped in the quadratic lattice of a BCC material (T-site) [44].

The hydrogen content after NDH-HT was measured by thermal desorption spectrometry (TDS). In order to check that the material structure had not been sensitized by NDH-HT the microstructure was etched, and this confirmed that chromium carbides did not segregate at grain boundaries. As further evidence of the avoidance of sensitizing, the Vickers hardness before and after NDH-HT was found to be largely unchanged (for Type $304 H V=176$ before and 172 after NDH-HT, for Type 316L $H V=157$ before and 163 after NDH-HT).

Figure 9 shows the hydrogen emission intensity profile (Curve C), measured using TDS, for a specimen after NDH-HT. As can be seen in the figure, NDH-HT substantially decreases the peak value of the hydrogen emission intensity profile, and the total emission is also decreased from 2.6 wppm to 0.4 wppm.

Figure 12 shows the fatigue crack growth behavior of NDH-HT specimens. Fatigue tests were carried out at a frequency of $1.5 \mathrm{~Hz}$ until a crack had grown to $200 \mu \mathrm{m}$ in length, including the hole diameter $(100 \mu \mathrm{m})$, and the test frequency was then changed to $0.0015 \mathrm{~Hz}$. Surprisingly, the fatigue crack growth rate of an NDH-HT specimen was substantially decreased in comparison with a hydrogen-charged specimen, and even in comparison with an uncharged specimen. Further evidence of the effect of NDH-HT was seen in the striation height-spacing ratios $(H / s)$ which are shifted to higher values. The above facts are definite proof that even the non-diffusible hydrogen contained in ordinary solution treated austenitic stainless steels influences fatigue crack growth rates. From the result of this experiment we can identify the following two reasons for the increase in fatigue crack 
rates, at the very low test frequency of $0.0015 \mathrm{~Hz}$, in solution treated uncharged specimens, which naturally contain hydrogen at the level of $2 \sim 3 \mathrm{wppm}$.

(1) At a very low test frequency, of the order of $0.0015 \mathrm{~Hz}$, there is sufficient time for hydrogen to be transported to fatigue crack tips through lattice defects such as edge dislocations. In this case, it is presumed that the probability of the movement of the hydrogen out of O-sites is increased by the fluctuation of the potential energy due to lattice deformation under very low stress frequencies.

(2) As austenite at fatigue crack tips partially transforms to strain-induced martensites, the binding energy between hydrogen and a trapping site is decreased, and at the same time the locally transformed martensites at fatigue crack tip enhances the diffusion and concentration of hydrogen trapped in austenites to fatigue cracks[38, 45].

For example, at $0.0015 \mathrm{~Hz}$, with $\Delta K=10 \mathrm{MPa} \cdot \mathrm{m}^{1 / 2}$ for which the plastic zone size under plane strain is approximately $20 \mu \mathrm{m}$ based on simple application of the Dugdale model, during one fatigue cycle (11 min) hydrogen can move approximately $0.4 \mu \mathrm{m}$ in plastically deformed austenites having a slightly higher diffusion rate than that for an undeformed structure, whereas it can move approximately $3.5 \mu \mathrm{m}$ through transformed martensites[41].

Thus, it is vitally important to take the effect of loading frequency into consideration for the prediction of fatigue lives and the safety of infrastructures and components which, in actual service, are used in hydrogen environments. Current fatigue data obtained by conventional accelerated tests should therefore not be used for design to ensure the long term safety of hydrogen energy systems. Therefore, fatigue test methods must be reviewed from the viewpoints both of test frequency and of hydrogen content.

F. Hydrogen-induced striation formation mechanism. Based on the data for striation shape, which involves information on the crack growth mechanism, we will discuss the mechanisms of crack tip opening, crack growth, and decrease in $H / s$ induced by hydrogen. We will also discuss the mechanisms related, not only to the mechanism of hydrogen embrittlement in fatigue, but also to the basic mechanism of hydrogen embrittlement in static fracture.

The distributions of maximum shear stress and of hydrostatic tensile stress, ahead of the crack tip, under plane strain can be easily calculated by the elastic solution of crack. In the case when there is no hydrogen, slip from the crack tip occurs in the $75.8^{\circ}$ direction, where the shear stress has its maximum under plane strain. The slip in the $75.8^{\circ}$ direction causes both crack tip blunting and crack growth at the initial stage of loading. Under a given load level crack tip blunting occurs as a crack grows and, finally, at the maximum load crack growth is saturated. This mechanism has been well known in previous studies on metal fatigue [46-49]. On the other hand, for the case when hydrogen is present, Sofronis et al. [50] showed, by numerical analysis of hydrogen diffusion near the crack tip, that hydrogen diffuses to, and concentrates at, the region where the hydrostatic tensile stress has its maximum. Tabata, Birmbaum and et al. [18] suggested, through TEM observation of the interaction between dislocations and hydrogen, that yield stress decreases as a function of hydrogen pressure. Considering their experimental result, it is therefore presumed that yield stress decreases at a region where hydrogen concentrates. As a result, crack tip blunting and crack growth both occur during the whole load cycle. Namely, even if crack tip blunting occurs at a given load level that is below the maximum load, further slip takes place at the growing crack tip where hydrogen repeatedly concentrates. This further slip reduces crack tip blunting in the $75.8^{\circ}$ direction; both crack tip blunting and crack growth occur in a coupled manner during the whole load cycle. As shown in Fig. 16 , the fatigue crack growth mechanism of ductile materials is based on striations formed by slip at a crack tip. This differs from the static fracture mechanism of BCC metals. However, the diffusion and concentration behaviour of hydrogen near a crack tip, or near a notch root, is similar in both FCC and BCC metals (see Appendix A). Furthermore, with decreasing fatigue test frequency, there is sufficient time for hydrogen to diffuse towards crack tips, and a large amount of hydrogen concentrates near crack tips. As a result, a crack continues to grow before the crack tip becomes fully blunt. 


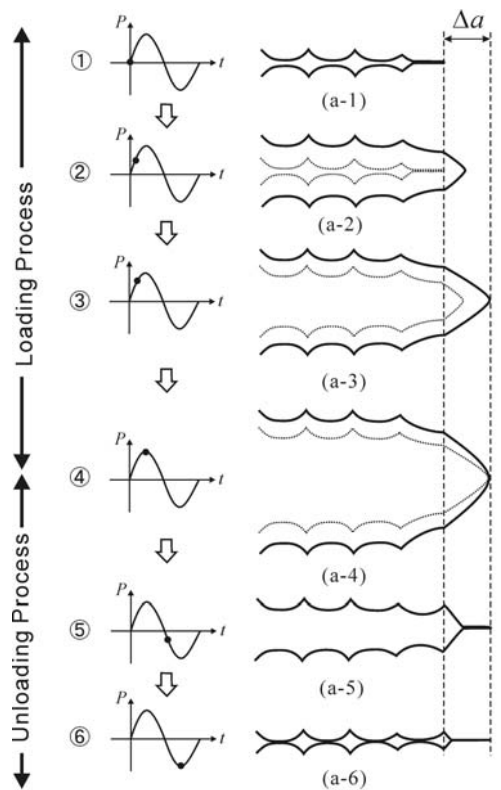

(a) No Hydrogen Effect $\mid$ [49]

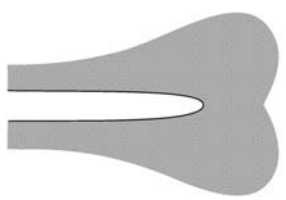

(c)

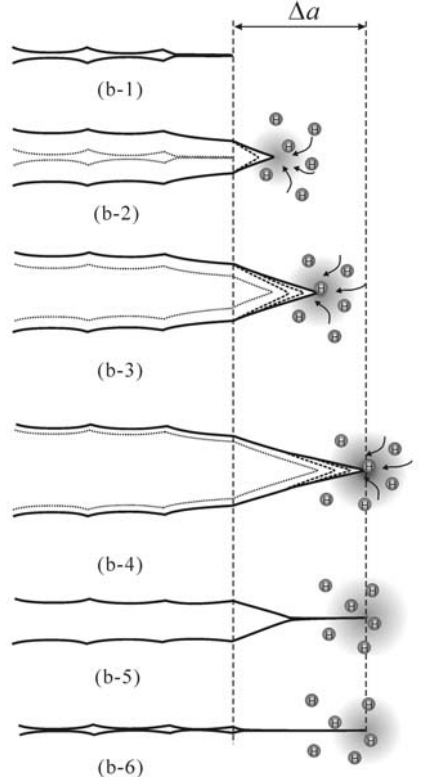

(b) Hydrogen Effect

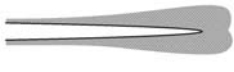

(d)

Fig. 16 Crack tip opening and striation formation mechanism in fatigue: (a) no hydrogen effect, (b) hydrogen effect, (c) schematic image of thick plastic zone wake produced at a crack under no hydrogen, and (d) schematic image of shallow plastic zone wake produced at a crack under hydrogen effect[41].

It is well known that there are three types of crack closure which control fatigue crack growth [51-53]. From the viewpoint of plasticity-induced crack closure [51], it follows from the above discussion that the amount of plastic deformation (plastic zone size) at the maximum load, $P_{\max }$, is smaller in the presence of hydrogen than in its absence. Figures 16(a) and (b) illustrate the effect of hydrogen on the crack closure mechanism during one load cycle. Figure 16(a-2) shows the crack opening behavior on the way to the maximum load in the absence of hydrogen. The crack tip opening displacement reaches its saturated value at a given load level and crack growth ceases. As shown in Fig. 16(b-2), however, hydrogen concentrates near the crack tip in the presence of hydrogen. Hydrogen concentration enhances further crack opening by slip, and crack growth continues. Since the corresponding plastic zone at the crack tip does not become large, the plastic zone wake which remains on the fracture surface is shallow. Figure 16(c) and (d) are schematic illustrations of plastic zone wakes with and without hydrogen. Ritchie et al. [54, 55] pointed out that the reason for the increase in crack growth rates of a Cr-Mo steel, in a hydrogen gas environment, is the increase in $\Delta K_{\text {eff }}$ due to the absence of oxide induced crack closure. However, as shown in Fig. 16, hydrogen influences all three types of crack closure mechanisms. In particular, the effect of hydrogen on plasticity-induced crack closure is crucially important for all three types of crack closure mechanism. 
This phenomenon results both in decrease in the height of striation and in decrease in the crack opening load (decrease in $\Delta K_{\text {op }}$ and increase in $\Delta K_{\text {eff }}$ ).

As has been described in the previous paragraph, a crack grows continuously during loading, in the presence of hydrogen, even before the crack opening displacement reaches its maximum value. Consequently, the crack tip shape at the maximum load is sharper in the presence of hydrogen than in its absence. The effect of hydrogen on plastic deformation at a crack tip may be reduced during unloading. This is because the stress field at the crack tip becomes compressive. Nevertheless, it is presumed that the vertical distance between the peak and the valley of a striation becomes small. This is because the crack opening displacement at the maximum load is small in the presence of hydrogen, even though the amount of reverse slip is the same as that in air. This is the possible mechanism for the small ratio of striation height, $H$, to spacing $s, H / s$, in the presence of hydrogen.

\section{CONCLUSIONS}

The basic mechanism of hydrogen embrittlement in the fatigue of a Cr-Mo steel JIS SCM435 and austenitic stainless steels, of Type 304 and Type 316L, has been made clear on the basis of the effects of hydrogen and load frequency on fatigue crack growth rates. The conclusions can be summarized as follows.

Conclusions for a Cr-Mo steel:

(1) With decreasing load frequency, the fatigue crack growth rate for the hydrogen charged specimens increased significantly. However, there is the upper bound of the acceleration of $\mathrm{d} a / \mathrm{d} N$ and it is 30 times of $\mathrm{d} a / \mathrm{d} N$ for uncharged specimens.

(2) The two step fatigue tests for different load frequencies $f=2 \mathrm{~Hz}$ and $0.02 \mathrm{~Hz}$ made clear the mechanism of slip localization and linear crack path in the fatigue of hydrogen carged specimens. The fatigue crack path of uncharged specimens was monotonically inclined and curved regardless of load frequency due to the growth of plastic zone with increasing $\Delta K$. However, the fatigue crack path of hydrogen charged specimens changed from a inclined and curved shape to a linear and straight crack by switching $f$ from $f=2 \mathrm{~Hz}$ to $0.02 \mathrm{~Hz}$. This is due to the slip localization and decrease in plastic zone size in presence of hydrogen.

Conclusions for austenitic stainless steels:

(1) Although one of the major models assumed to explain hydrogen embrittlement has been the hydrogen decohesion hypothesis, the basic phenomenon of hydrogen embrittlement during fatigue loading is not caused by lattice decohesion. The basic mechanism is hydrogen diffusion to, and concentration at, crack tips. This leads to the activation of hydrogen induced slip deformation.

(2) Fatigue crack growth rates are increased in the presence of hydrogen, and are strongly dependent on cyclic load frequency. The dependency on load frequency is a consequence of the very low hydrogen diffusion rate in austenitic stainless steels, which have the FCC structure. The local and partial strain induced martensitic transformation at crack tips, which provides the hydrogen diffusion highway $[38,45]$, also contributes to the concentration of hydrogen.

(3) The non-diffusible (irreversible) hydrogen at a level of $2 \sim 3 \mathrm{wppm}$, which is trapped at O-sites in the lattice of ordinarily heat-treated austenitic stainless steels, has been ignored for the last 40 years as an important factor causing HE. However, it has been found in the present study that the non-diffusible hydrogen definitely increases fatigue crack growth rates when the loading frequency is reduced to $0.0015 \mathrm{~Hz}$.

(4) If the non-diffusible hydrogen is removed, down to the level of $0.4 \mathrm{wppm}$, by a special heat treatment, then the damaging influence of the loading frequency disappears, and fatigue crack growth rates are significantly decreased. The special heat treatment (NDH-HT) is a new method of heat treatment, which is essentially different from conventional heat treatments such as 'baking'. The new heat treatment method will be useful to improve material resistance to HE. 
(5) The hydrogen-enhanced localized and discrete slip at fatigue crack tips changes the mechanism of crack opening and closing behaviour, and as a result it particularly increases fatigue crack growth rates at low loading frequency. This mechanism also produces a unique striation morphology in the presence of hydrogen.

\section{ACKNOWLEDGEMENT}

This research has been supported by the NEDO project "Fundamental Research Project on Advanced Hydrogen Science (2006-2012)".

The author thanks Prof. S. Matsuoka, Dr. T. Kanezaki and Dr. Y. Mine for their kind cooperations to the preparation of this paper.

\section{APPENDIX A}

The hydrogen-charged specimens show a peculiar void growth inside the specimen in tensile test. Figure A1 shows an interesting difference of void growth behaviour between the uncharged specimen (Fig. A1(a)) and the hydrogen-charged specimen (Fig. A1(b)). The basic mechanism of the void growth lateral to tensile axis in the hydrogen-charged specimen (Fig. A1(b) and (c)) can be considered consistent with that of fatigue crack growth(Fig. 16).

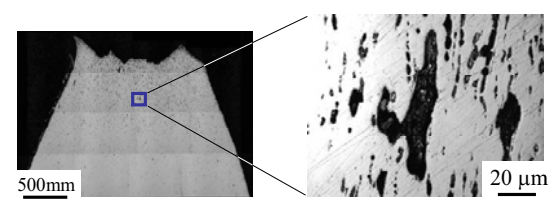

(a) Uncharged (0.05ppm)

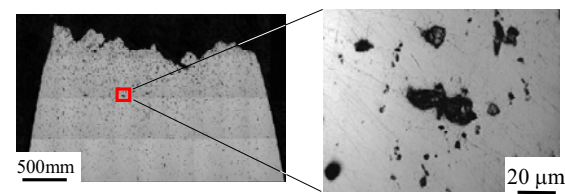

(b) Hydrogen charged (0.91ppm)

Voids in longitudinal cross section of tensile fractured specimens.

Hydrogen
$\left\{\begin{array}{c}\cdot \text { Voids are elongated in the direction perpendicular } \\ \text { to the tensile axis. } \\ \cdot \text { Nucleation of voids occurs at the lower true strain. }\end{array}\right.$
$\Rightarrow$ Hydrogen enhances
Localized Slip Deformation.

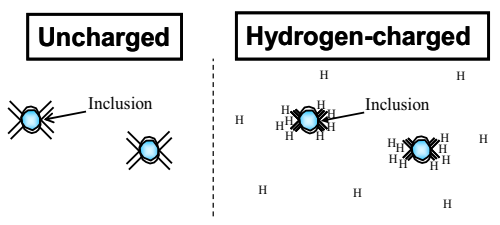

(a) Nucleation

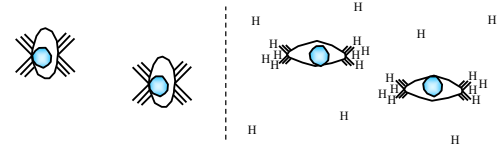

(b) Growth

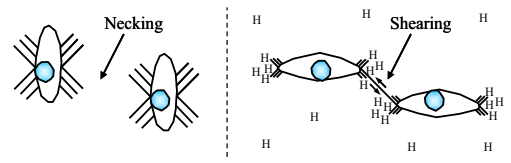

(c) Coalescence

Schematic illustration of nucleation, growth and coalescence of voids.

Fig. A1 Development of voids in tensile test of the hydrogen charged specimen of a pipe line steel, JIS-SGP $(0.078 \%$ carbon steel $)[56]$ 


\section{7th European Conference on Fracture 2.5 September,2008, Brno, Czech Republic}

\section{References}

[1] K. Farrell, A. G. Quarrell: J. of the Iron and Steel Institute, (1964), pp.1002-1011.

[2] D. S. Shih, I. M. Robertson, H. K. Birnbaum: Hydrogen embrittlement of $\alpha$ titanium: in situ TEM studies. Acta Metall., 36(1988), pp.111-124.

[3] A. M. Brass, J. Chene: Material Sci. and Engng, A242(1998), pp.210-221.

[4] H. K. Birnbaum, P. Sofronis: Material Sci. and Engng, A176 (1994), pp.191-202.

[5] W. R. Heller: Acta Metall., 9(1961), pp.600-613.

[6] H. Matsui, H. Kimura: Mater. Sci. Engng, 40(1979), pp.227-234.

[7] H. Kimura, H. Matsui: Scripta Metallurgica, 13(1979), pp.221-223.

[8] J. P. Hirth: Metall. Trans. A, 11A(1980), pp.861-890.

[9] J. F. Dufresne, A. Seeger: Hydrogen relaxation in $\alpha$-iron. Groh P. and Moser P., Phys. Stat. Sol. (a), 36(1976), pp.579-589.

[10] O. N. Senkov, J. J. Jonas: Metall. Mater. Trans. A, 27A(1996), pp.1877-1887.

[11] J. J. Au, H. K. Birnbaum: Scripta Metallurgica, 7(1973), pp.595-604.

[12] T. Magnin, C. Bosch, K. Wolski, D. Delafosse: Mater. Sci. Eng., A314(2001), pp.7-11.

[13] J. A. Clum: Scripta Metallurgica, 9(1975), pp.51-58.

[14] H. K. Birnbaum, I. M. Robertson, P. Sofronis, in: J. Lepinoux (Ed.), Multiscale Phenomena in Plasticity, Kluwer Academic Publishers. (2000).

[15] F. Mignot, V. Doquet, C.Sarrazin-Baudoux: Mater. Sci. Eng., A380 (2004), pp.308-319.

[16] A. R. Troiano: Trans. ASM, Vol. 52(1960), pp. 54-80.

[17] O. A. Oriani and P. H. Josephic: Acta Metall., Vol. 22(1974), pp. 1065-1074.

[18] T. Tabata and H. K. Birnbaum: Scripta Metall., Vol. 17(1983), pp. 947-950.

[19] I. M. Robertson and H. K. Birnbaum: Acta Metall., Vol. 34(1986), pp. 353-366.

[20] R. M. Vennett and G. S. Ansell: Trans. ASM, Vol. 60(1967), pp. 242-251.

[21] R. B. Benson Jr, R. K. Dann and L. W. Roberts Jr.: Trans. Metall. Soc. AIME, Vol. 242(1968), pp. 2199-2205.

[22] R. Lagneborg: J. Iron and Steel Inst., Vol. 207(1969), pp. 363-366.

[23] C. D. Beachem: Metall. Trans., Vol. 3(1972), pp. 437-451.

[24] R. Garber, I. M. Bernstein and A. W. Thompson: Scripta Metall., Vol. 10(1976), pp. 341-345.

[25] H. Cialone and R. J. Asaro: Metall. Trans., Vol. 10A(1979), pp. 367-375.

[26] D. Eliezer, D. G. Chakrapani, C. J. Altstetter and E. N. Pugh: Metall. Trans., Vol. 10A(1979), pp. 935-941.

[27] Y. Rosenthal, M. M.-markowitch, A. Stern and D. Eliezer: Scripta Metall., Vol. 15(1981), pp. 861-866.

[28] S. Singh and C. Altstetter: Metall. Trans., Vol. 13A(1982), pp. 1799-1808.

[29] R. E. Stoltz, N. R. Moody and M. W. Perra: Metall. Trans., Vol. 14A(1983), pp. 1528-1531.

[30] P. Rozenak, I. M. Robertson and H. K. Birnbaum: Acta Metall., Vol. 38(1990), pp. 2031-2040. 
[31] P. J. Ferreira, I. M. Robertson and H. K. Birnbaum: Acta Metall., Vol. 46(1998), pp. 1749-1757.

[32] A. Valiente, L. Caballero and J. Ruiz: Nucl. Eng. Design, Vol. 188(1999), pp. 203-216.

[33] M. Nagumo, M. Nakamura and K. Takai: Metall. Mater. Trans., Vol. 32A(2001), pp. 339-347.

[34] Y.(Yukitaka) Murakami, T. Ueda, T. Nomoto, Y.(Yasuo) Murakami, M. Ohori: J. Soc. Mater. Sci., Jpn, Vol.48, No.10(1999), pp.1112-1117.

[35] Y. Murakami: Metal Fatigue: Effects of Small Defects and Nonmetallic Inclusions, Elsevier, Oxford, UK(2002).

[36] Y.(Yukitaka) Murakami, H. Konishi, K. Takai and Murakami Y.(Yasuo): Tetsu-to-Hagane, 86 (2000), pp.777-783.

[37] H. Kawazoe, S. Goto, T. Otsuka, K.Hashizume and T. Tanabe: private communication(2005).

[38] T. Kanezaki, C. Narazaki, Y. Mine, S. Matsuoka and Y. Murakami: Int. J. HYDROGEN ENERGY, Vol. 33(2008), pp.2604-2619.

[39] Y. Mine, C. Narazaki, T. Kanezaki, S. Matsuoka and Y. Murakami: J. Iron Steel Inst. Jpn., Vol. 93(2007), pp.247-256.

[40] H. Tanaka, N. Honma, S. Matsuoka and Y. Murakami: Trans. JSME, A73-736(2007), pp. 1358-1365

[41] Y. Murakami, T. Kanezaki, Y. Mine and S. Matsuoka: Metallurgical and Materials Trans., Vol. 39A(2008), pp.1327-1339

[42] P. Smith and A. T. Stewart: Metal. Sci., Vol.13(1979), pp. 429-435.

[43] K. Furukawa, Y. Murakami and S. Nishida: Int. J. Fatigue, Vol. 20(1998), pp.509-516.

[44] Y. Fukai: The Metal-Hydrogen System: basic bulk properties, Springer(1993).

[45] Y. Murakami: in Proceedings of International Hydrogen Energy Development Forum, Fukuoka, Japan(2007), pp.96-105.

[46] C. Laird: ASTM STP., Vol. 415(1967), pp.131-168.

[47] R. M. N. Pelloux: Trans. ASM, Vol. 62(1969), pp.281-285.

[48] P. Neumann: Acta Metall., Vol. 22(1974), pp.1155-1165.

[49] C. H. Bichler and R. Pippan, in: Engineering Against Fatigue, J. H. Beynon and others, eds., Balkema, Rotterdam(1999), pp.211-218.

[50] P. Sofronis and R. M. McMeeking: J. Mech. Phys. Solids, Vol.37(1989), pp.317-350.

[51] W. Elber: ASTM STP., Vol.486(1971), pp. 230-242.

[52] R. O. Ritchie, S. Suresh, C. M. Moss: Trans. ASME, J. Eng. Mater. Tech., Vol.102(1980), pp. 293-299.

[53] K. Minakawa and A. J. McEvily: Scripta Metall., Vol. 15(1981), pp. 633-636.

[54] J. Toplosky and R. O. Ritchie: Scripta Metall., Vol. 15(1981), pp. 905-908.

[55] S. Suresh and R. O. Ritchie: Eng. Fract. Mech., Vol. 18(1983), pp. 785-800.

[56] T. Matsuo, N. Honma, S. Matsuoka and Y. Murakami: submitted elsewhere. 